\title{
A new polymorphism in the Growth and Differentiation Factor 9 (GDF9) gene is associated with increased ovulation rate and prolificacy in homozygous sheep
}

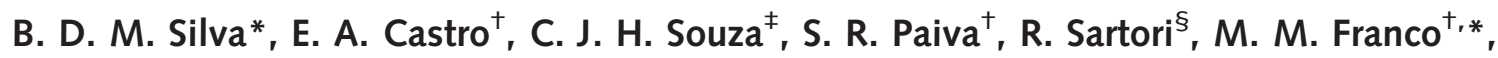 \\ H. C. Azevedo", T. A. S. N. Silva*, A. M. C. Vieira*, J. P. Neves* and E. O. Melo ${ }^{+*}$ \\ *Universidade de Brasília, Brasília, Brazil. †Embrapa Recursos Genéticos e Biotecnologia, Brasília, Brazil. "Embrapa Pecuária Sul, Bagé, Brazil. \\ §Universidade de São Paulo, São Paulo, Brazil. "Embrapa Tabuleiros Costeiros, Aracaju, Brazil
}

\section{Summary}

\begin{abstract}
Brazilian Santa Inês (SI) sheep are very well-adapted to the tropical conditions of Brazil and are an important source of animal protein. A high rate of twin births was reported in some SI flocks. Growth and Differentiation Factor 9 (GDF9) and Bone Morphogenetic Protein 15 (BMP15) are the first two genes expressed by the oocyte to be associated with an increased ovulation rate in sheep. All GDF9 and BMP15 variants characterized, until now, present the same phenotype: the heterozygote ewes have an increased ovulation rate and the mutated homozygotes are sterile. In this study, we have found a new allele of GDF9, named $\mathrm{FecG}^{E}$ (Embrapa), which leads to a substitution of a phenylalanine with a cysteine in a conservative position of the mature peptide. Homozygote ewes presenting the $\mathrm{FecG}^{E}$ allele have shown an increase in their ovulation rate $(82 \%)$ and prolificacy $(58 \%)$. This new phenotype can be very useful in better understanding the genetic control of follicular development; the mechanisms involved in the control of ovulation rate in mammals; and for the improvement of sheep production.
\end{abstract}

Keywords growth factor, Ovis aries, prolificacy.
Some breeds of sheep are naturally prolific and they are very informative for the study of reproductive genetics and physiology. It is postulated that GDF9 and BMP15 may form non-covalent homo and heterodimers in vivo and, in a species-specific way, modulate the ovulation rate in mammals (Moore et al. 2004). The TGF $\beta$-family member BMP 15 was the first gene to be associated with increased ovulation rate in Inverdale $\left(\mathrm{Fec} \mathrm{X}^{I}\right.$ polymorphism) and Hanna $\left(\mathrm{FecX} \mathrm{X}^{H}\right)$ sheep (Galloway et al. 2000). Soon after, the Booroola variant $\left(\mathrm{FecB}^{B}\right)$ was found in the BMPR1B gene of Merino Booroola (Mulsant et al. 2001; Souza et al. 2001; Wilson et al. 2001). The BMPR1B, together with its partner BMPRII, is responsible for the BMP15 signalling in the ovarian follicles (Moore et al. 2003). The last major gene found to be associated with prolific phenotype was GDF9, in which a polymorphism $\left(\mathrm{FecG}^{\mathrm{H}}\right)$ found in Cambridge and F700-Belclare sheep is responsible for an increased ovulation rate in heterozygotes and sterility in homozygotes, in a way very similar to all BMP15 variants (Hanrahan et al.

Address for correspondence

E. O. Melo, Embrapa Recursos Genéticos e Biotecnologia PBI sala 7B, PqEB Final W5 Norte, Asa Norte, Brasília 70770-9001, Brazil.

E-mail: eom@cenargen.embrapa.br

Accepted for publication 15 April 2010
2004; Bodin et al. 2007; Martinez-Royo et al. 2008; Monteagudo et al. 2008).

Besides the GDF9 and BMP15 activities during cumulus expansion, oocyte maturation and ovulation (Elvin et al. 1999, 2000; Gui \& Joyce 2005; Yoshino et al. 2006), these two paracrine factors play important roles during many steps of follicular development. They influence follicle growth (Dong et al. 1996; Nilsson \& Skinner 2002), cumulus and granulosa cell proliferation (Hayashi et al. 1999; Gilchrist et al. 2006; Spicer et al. 2006), cell-survival signalling (Hussein et al.2005; Orisaka et al. 2006) and act as modulators of many other growth-factors and endocrine hormones (Juengel et al. 2004). As a result of their role in the folliculogenesis, the availability of GDF9 and BMP15 polymorphisms can be very useful in the study of animal reproductive genetics and physiology. In this study we have shown, for the first time, a polymorphism in the GDF9 gene that increases the ovulation rate in homozygotes, without sterility, in sheep.

In this study, 23 ewes (Ovis aries) from a Santa Inês (SI) population with a history of multiple births (twin and triplet births) were investigated for SNPs in the BMP15 and GDF9 genes. The ewes were genotyped for the Booroola SNP $\left(F e c B^{B}\right)$ as previously described (Wilson et al. 2001). Subsequently, exon 2 of the GDF9 and BMP15 genes were 
screened for SNPs by DNA sequencing of PCR amplicons using the following primers: GDF9 (forward 5'-GGAGAAA AGGGACAGAAGC; reverse 5'-ACGACAGGTACACTTAGT); and BMP15 (forward 5'-GGCTGCTTGTCAGTTTGTAC; reverse 5'-GAGCACTTTCAGATTTAA) (see Appendix S1 for details). Seven (GI to GVII) single nucleotide polymorphisms (SNPs) were found in GDF9 (Table A1, additional data). Only the GVII polymorphism is a non-conservative change in position 345 (phenylalanine to cysteine), which was detected in $43 \%$ of the sequenced animals, and it is in the mature peptide of GDF9. This polymorphism provokes a change in a residue which is $100 \%$ conserved in the sequence of four representative mammalian species (FigureA1 in Appendix S1), and was named $F e c G^{E}$ (GenBank FJ429111) according to the previous nomenclature for the high fertility GDF9 allele (FecG ${ }^{H}$ ) (Hanrahan et al. 2004).

To find the frequency of the $\mathrm{FecG}^{E}$ polymorphism, a total of 334 animals from a separate flock (Appendix S1) that had not been selected for prolificacy have had their genotypes identified by a PCR-RFLP strategy (Appendix S1). All data about the parturition of these ewes during the period of 2002 to 2008 were collected, and the association between the number of lamb births and genotypes was tested. The genotype distribution and allele frequency were analysed by the Chi-square test. A difference $(P<0.001)$ in the frequency of $\mathrm{FecG}^{E}$ and $\mathrm{FecG}^{+}$alleles, as well as in the genotype distribution, was observed between the randomly selected and the prolificacy-selected flocks (Table 1).

To investigate the association between the $\mathrm{FecG}^{E}$ genotypes $(\mathrm{E} / \mathrm{E},+/ \mathrm{E}$, and $+/+)$ and the ovulation rate, 39 ewes $\left(15 \mathrm{FecG}^{+/+}, 15 \mathrm{FecG}^{+/ E}\right.$ and $\left.9 \mathrm{FecG}^{\mathrm{E} / \mathrm{E}}\right)$ were selected from the genotyped flocks and submitted to oestrus synchronization. The animals were oestrus synchronized twice, with eCG and PGF2alpha-based protocols in a cross-over design (Appendix S1). Eleven days after the last oestrus detection, laparoscopy was performed as previously described (Killen \& Caffery 1982) to infer ovulation rate by counting corpora lutea (CL). At the end of the breeding season, pregnancy status was evaluated by ultrasound. All animals submitted to laparoscopy had their GDF9 and BMP15 exon 2 sequenced to confirm the $\mathrm{FecG}^{E}$ genotyping and to verify that there was no other characterized polymorphism

Table 1 Genotypic and allelic frequencies of $F e c G^{E}$ in Santa Inês flocks.

\begin{tabular}{lllll}
\hline \multirow{2}{*}{ SI Flock } & Genotype & $\begin{array}{l}\text { Frequency } \\
(N)\end{array}$ & Allele & $\begin{array}{l}\text { Frequency } \\
(N)\end{array}$ \\
\hline Prolific-selected $^{\mathrm{a}}$ & $+/+$ & $0.174(4)$ & $\mathrm{FecG}^{+}$ & $0.478(22)$ \\
& $+/ E$ & $0.609(14)$ & $\mathrm{FecG}^{E}$ & $0.522(24)$ \\
& E/E & $0.217(5)$ & - & - \\
Randomly selected $^{\mathrm{b}}$ & $+/+$ & $0.656(219)$ & $\mathrm{FecG}^{+}$ & $0.808(540)$ \\
& $+/ E$ & $0.305(102)$ & $\mathrm{FecG}^{E}$ & $0.192(128)$ \\
& E/E & $0.0389(13)$ & - & -
\end{tabular}

Distinct letters are different $(P<0.001)$ for genotype distribution. associated with ovulation rate. The animals were handled in accordance with pertinent Brazilian legislation and following Embrapa's procedures for animal care.

The CL number and the number of lamb births were fitted to the GLM (Generalized Linear Model), where the Poisson distribution was attributed to the ovulation rate, pregnancy and lambing data. In this analysis, the lamb count was considered as response variable, measured for each animal in seven different breeding seasons from 2002 to 2008 (time variable). To measure the influence of genotype over the offspring number through the time, a generalized linear mixed model (GLMM, SAS software) was applied. The offspring number $y_{i j}$ of the $i^{\text {th }}$ animal at the $j^{\text {th }}$ time was modelled as the per following model:

$$
\begin{aligned}
y_{i j} \mid \gamma_{j} & \sim \operatorname{Poisson}\left(\mu_{i j}\right) \\
\gamma_{j} & \sim N\left(0, \sigma^{2}\right) \\
\mu_{i j} & =\exp \left(\beta_{0}+\beta_{1} X 1_{i}+\beta_{2} X 2_{i}+\beta_{3} Z_{i j}+\gamma_{i}\right) \\
\operatorname{Var}\left(y_{i j} \mid \gamma_{j}\right) & =\sigma^{2} \mu_{i j},
\end{aligned}
$$

where $y_{i j}$ follows the Poisson distribution conditioned to the random effect for animal $\gamma_{i}$, which was assumed to be normally distributed with variance $\sigma^{2}$. The expected mean $\mu_{i j}$ is a non-linear function of the effects of genotype $\left(\beta_{1}\right.$ and $\left.\beta_{2}\right)$, time when the counting was made $\left(\beta_{3}\right)$ and the random effect because of each animal. The variance for $y_{i j}$ irrespective of the random effect $\gamma_{i}$ is $\operatorname{Var}\left(y_{i j}\right)=\sigma^{2} \mu_{i j}$, where the extra (or sub) variation is taken into account. The estimate for $\sigma^{2}$ is 0.1696 (standard error $=0.0087$ ), indicating a strong under-dispersion, but this is correctly modelled by GLMM (see Appendix S1, SAS output in additional data).

The parturition data of the 334 genotyped ewes showed a difference $(P<0.0001)$ in the prolificacy amongst the groups (Table 2). Regarding the ovulation rate, it was greater $(P<0.001)$ in the homozygote $(\mathrm{E} / \mathrm{E})$ group, which showed an $82 \%$ increase in CL average (2.22 \pm 0.12 , Fig. 1a), as well as the highest frequency (96.3\%) of multiple-ovulating ewes (Fig. 1b), when compared with $+/ \mathrm{E}$ and $+/+$ groups. The heterozygote group $(+/ \mathrm{E})$ presented no difference $(P=0.612)$ in CL average $(1.34 \pm 0.08)$ or in the frequency $(31.8 \%)$ of ewes with multiple ovulations (Fig. $1 \mathrm{a}$ and b), when compared with the wild-type ewes $(1.22 \pm 0.11$ and $14.6 \%$

Table 2 The effect of of $F e c G^{E}$ in Santa Inês prolificacy.

\begin{tabular}{lll}
\hline SI Flock (F1) & Genotype & $\begin{array}{l}\text { Prolificacy of F1 } \\
\text { (mean; }[95 \% \mathrm{CI}])\end{array}$ \\
\hline Randomly selected & $+/+$ & $1.13 ;[1.11,1.16]^{\mathrm{a}}$ \\
& $+/ E$ & $1.44 ;[1.41,1.48]^{\mathrm{b}}$ \\
& E/E & $1.78 ;[1.69,1.87]^{\mathrm{c}}$ \\
\hline
\end{tabular}

Distinct letters are different $(P<0.001)$.

Non-selected SI; $N=334$ ewes $(219+/+; 102+/$ E and 13 E/E), called F1.

Prolificacy = mean of 764 offspring (F2) from the 334 genotyped ewes (F1); separated according to their genotype category. 
(a)

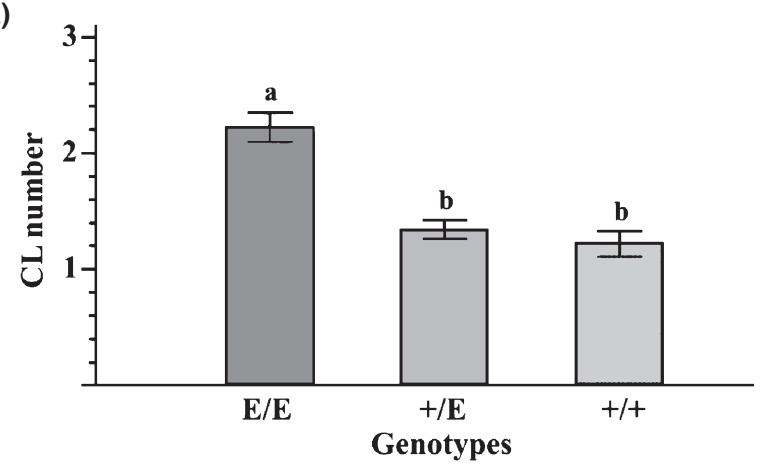

(b)

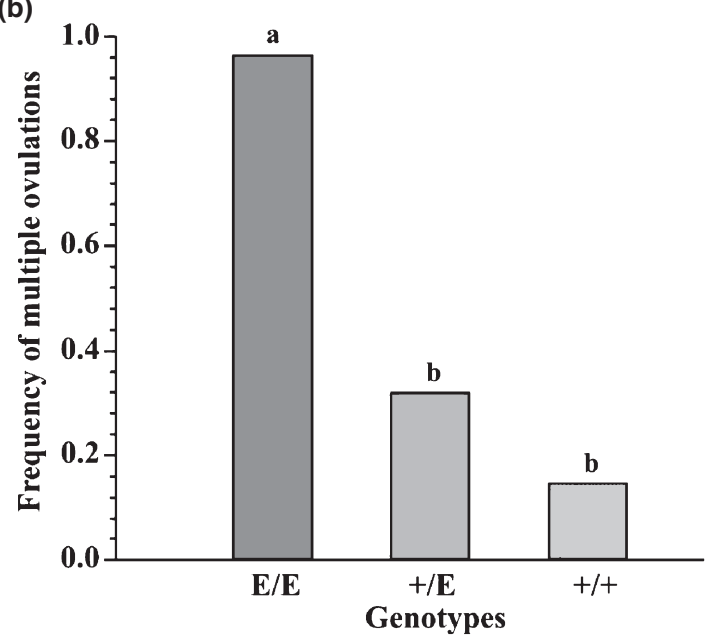

(c)

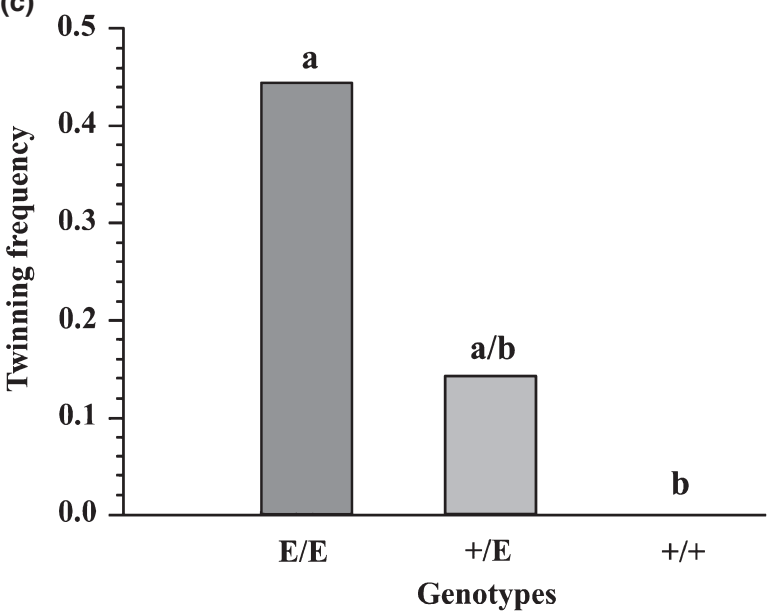

Figure 1 The effect of genotypes on ovulation. (a) The average number of corpora lutea $(\mathrm{CL})$ per ewe in each genotype: $\mathrm{E} / \mathrm{E}\left(\mathrm{Fec} \mathrm{G}^{E}\right.$ in homozygosis) $N=9,+/ E$ ( $F e c G^{E}$ in hereozygosis) $N=15$ and $+/+$ (without $F e c G^{E}$ allele) $N=15$. The $C L$ data are presented as mean $\pm \mathrm{SE}$. (b) The frequency of multiple-ovulating ewes $(\geq 2 \mathrm{CL})$ in each genotype as described in (a). (c) The frequency of twinning scored by ultrasonography at the 45th day of gestation in each genotype: $E / E$ $(N=9),+/ E(N=14)$ and $+/+(N=14)$. Groups with different letters $\operatorname{differ}(P<0.001$; Figures $1 \mathrm{a}$ and $1 \mathrm{~b})$ or $(P=0.0136$; Figure $1 \mathrm{c})$.

respectively). We observed a genotype effect on the number of twins per ewe $(P=0.0136)$; E/E ewes showed $44 \%$ of twin-pregnancy, while no twin-pregnancy was observed in
+/+ ewes (Fig. 1c). Moreover, the E/E ewes presented no observable effect of $F e c G^{E}$ other than the increased ovulation rate and twinning.

It has been suggested that increasing multiple births may be an efficient way to improve meat production per ewe, and an increase of $50 \%$ in total weight weaned per ewe lambing twins has been reported (Rajab et al. 1992). The increase of one extra CL and 58\% more lambs born observed in E/E ewes compared with +/+ was a strong evidence of the $\mathrm{FecG}^{E}$ effect on ovulation rate control and prolificacy, and represents a new phenotype for GDF9 in sheep. Our parturition data point to an additive effect for the $\mathrm{FecG}^{E}$ allele, despite no difference being observed in the ovulation rate between $+/+$ and $\mathrm{E} /+$ ewes. However, the allele interactions of $\mathrm{FecG}^{E}$ are certainly distinct from the over-dominant behaviour observed in $\mathrm{FecG}^{H}$ and all FecX alleles described until now. The E/E pregnancy and parturition data confirm that their oocytes were viable and fertile; which correlate with the increased prolificacy (number of lambs/ewe) observed amongst these animals. In this study, for the first time, a new SNP that increased the ovulation rate and prolificacy of homozygote sheep was documented for the GDF9 gene. This new genetic variant, together with the other documented variants in GDF9 and BMP15, can be very useful to obtain a better understanding of the genetic control of ovulation rate in mammals. Moreover, this major gene variant can be applied in breeding programmes by gene-assisted selection (GAS), aiming towards the improvement of sheep reproductive potential and production. However, further investigation is necessary to shed light on the allelic interactions of the $\mathrm{FecG}^{E}$ variant.

\section{Acknowledgements}

We thank Dr Margot A. N. Dode for her help in manuscript revision; Alexandre Lim, Rogério Tokarsky and Concepta M. Pimentel for their assistance with the animals; Joseane P. da Silva for statistical assistance. This work was supported by IFS, Sweden (Grant B/4317-1) and CNPq, Brazil (Grant 474619/2007-9).

\section{References}

Bodin L., Di Pasquale E., Fabre S., Bontoux M., Monget P., Persani L. \& Mulsant P. (2007) A novel mutation in the bone morphogenetic protein 15 gene causing defective protein secretion is associated with both increased ovulation rate and sterility in Lacaune sheep. Endocrinology 148, 393-400.

Dong J., Albertini D.F., Nishimori K., Kumar T.R., Lu N. \& Matzuk M.M. (1996) Growth differentiation factor-9 is required during early ovarian folliculogenesis. Nature 383, 531-5.

Elvin J.A., Clark A.T., Wang P., Wolfman N.M. \& Matzuk M.M. (1999) Paracrine actions of growth differentiation factor-9 in the mammalian ovary. Molecular Endocrinology 13, 1035-48.

Elvin J.A., Yan C. \& Matzuk M.M. (2000) Growth differentiation factor-9 stimulates progesterone synthesis in granulosa cells via a 
prostaglandin E2/EP2 receptor pathway. Proceedings of the National Academy of Sciences of the United States of America 97, 10288-93.

Galloway S.M., McNatty K.P., Cambridge L.M. et al. (2000) Mutations in an oocyte-derived growth factor gene (BMP15) cause increased ovulation rate and infertility in a dosage-sensitive manner. Nature Genetics 25, 279-83.

Gilchrist R.B., Ritter L.J., Myllymaa S., Kaivo-Oja N., Dragovic R.A., Hickey T.E., Ritvos O. \& Mottershead D.G. (2006) Molecular basis of oocyte-paracrine signalling that promotes granulosa cell proliferation. Journal of Cell Science 119, 3811-21.

Gui L.M. \& Joyce I.M. (2005) RNA interference evidence that growth differentiation factor-9 mediates oocyte regulation of cumulus expansion in mice. Biology of Reproduction 72, 195-9.

Hanrahan J.P., Gregan S.M., Mulsant P., Mullen M., Davis G.H., Powell R. \& Galloway S.M. (2004) Mutations in the genes for oocyte-derived growth factors GDF9 and BMP15 are associated with both increased ovulation rate and sterility in Cambridge and Belclare sheep (Ovis aries). Biology of Reproduction 70, 900-9.

Hayashi M., McGee E.A., Min G., Klein C., Rose U.M., van Duin M. \& Hsueh A.J. (1999) Recombinant growth differentiation factor-9 (GDF-9) enhances growth and differentiation of cultured early ovarian follicles. Endocrinology 140, 1236-44.

Hussein T.S., Froiland D.A., Amato F., Thompson J.G. \& Gilchrist R.B. (2005) Oocytes prevent cumulus cell apoptosis by maintaining a morphogenic paracrine gradient of bone morphogenetic proteins. Journal of Cell Science 118, 5257-68.

Juengel J.L., Bodensteiner K.J., Heath D.A., Hudson N.L., Moeller C.L., Smith P., Galloway S.M., Davis G.H., Sawyer H.R. \& McNatty K.P. (2004) Physiology of GDF9 and BMP15 signalling molecules. Animal Reproduction Science 82-83, 447-60.

Killen I.D. \& Caffery G.J. (1982) Uterine insemination of ewes with the aid of a laparoscope. Australian Veterinary Journal 59, 95.

Martinez-Royo A., Jurado J.J., Smulders J.P. et al. (2008) A deletion in the bone morphogenetic protein 15 gene causes sterility and increased prolificacy in Rasa Aragonesa sheep. Animal Genetics 39, 294-7.

Monteagudo L.V., Ponz R., Tejedor M.T., Lavina A. \& Sierra I. (2008) A 17 bp deletion in the Bone Morphogenetic Protein 15 (BMP15) gene is associated to increased prolificacy in the Rasa Aragonesa sheep breed. Animal Reproduction Science 110, 13946.

Moore R.K., Otsuka F. \& Shimasaki S. (2003) Molecular basis of bone morphogenetic protein-15 signaling in granulosa cells. Journal of Biological Chemistry 278, 304-10.

Moore R.K., Erickson G.F. \& Shimasaki S. (2004) Are BMP-15 and GDF-9 primary determinants of ovulation quota in mammals? TRENDS in Endocrinology and Metabolism 15, 356-61.
Mulsant P., Lecerf F., Fabre S. et al. (2001) Mutation in bone morphogenetic protein receptor-IB is associated with increased ovulation rate in Booroola Merino ewes. Proceedings of the National Academy of Sciences of the United States of America 98, 5104-9.

Nilsson E.E. \& Skinner M.K. (2002) Growth and differentiation factor-9 stimulates progression of early primary but not primordial rat ovarian follicle development. Biology of Reproduction 67, $1018-24$

Orisaka M., Orisaka S., Jiang J.Y., Craig J., Wang Y., Kotsuji F. \& Tsang B.K. (2006) Growth differentiation factor 9 is antiapoptotic during follicular development from preantral to early antral stage. Molecular Endocrinology 20, 2456-68.

Rajab M.H., Cartwright T.C., Dahm P.F. \& Figueiredo E.A. (1992) Performance of three tropical hair sheep breeds. Journal of Animal Science 70, 3351-9.

Souza C.J., MacDougall C., Campbell B.K., McNeilly A.S. \& Baird D.T. (2001) The Booroola ( $F e c B)$ phenotype is associated with a mutation in the bone morphogenetic receptor type 1 B (BMPR1B) gene. Journal of Endocrinology 169, R1-6.

Spicer L.J., Aad P.Y., Allen D., Mazerbourg S. \& Hsueh A.J. (2006) Growth differentiation factor-9 has divergent effects on proliferation and steroidogenesis of bovine granulosa cells. Journal of Endocrinology 189, 329-39.

Wilson T., Wu X.Y., Juengel J.L. et al. (2001) Highly prolific Booroola sheep have a mutation in the intracellular kinase domain of bone morphogenetic protein IB receptor (ALK-6) that is expressed in both oocytes and granulosa cells. Biology of Reproduction 64, 1225-35.

Yoshino O., McMahon H.E., Sharma S. \& Shimasaki S. (2006) A unique preovulatory expression pattern plays a key role in the physiological functions of BMP-15 in the mouse. Proceedings of the National Academy of Sciences of the United States of America 103, 10678-83.

\section{Supporting Information}

Additional supporting information may be found in the online version of this article.

Appendix S1 Additional data, materials and methods.

As a service to our authors and readers, this journal provides supporting information supplied by the authors. Such materials are peer-reviewed and may be re-organized for online delivery, but are not copy-edited or typeset. Technical support issues arising from supporting information (other than missing files) should be addressed to the authors. 